\title{
Laser Teeth Bleaching: Evaluation of Eventual Side Effects on Enamel and the Pulp and the Efficiency In Vitro and In Vivo
}

\author{
Roeland Jozef Gentil De Moor, ${ }^{1}$ Jeroen Verheyen, ${ }^{1,2}$ Peter Verheyen, ${ }^{3}$ Andrii Diachuk, ${ }^{1}$ \\ Maarten August Meire, ${ }^{1}$ Peter Jozef De Coster, ${ }^{1}$ Mieke De Bruyne, ${ }^{1}$ and Filip Keulemans ${ }^{1}$ \\ ${ }^{1}$ Department of Restorative Dentistry and Endodontology, Ghent Dental Laser Centre, Ghent Dental Photonics Research Cluster, \\ Ghent University, Ghent University Hospital, Dental School, De Pintelaan 185-P8, 9000 Gent, Belgium \\ ${ }^{2}$ Department of Clinical Neurosciences, John van Geest Centre for Brain Repair and Wellcome Trust-Medical Research Council \\ Stem Cell Institute, University of Cambridge, Clifford Allbutt Building, Cambridge Biosciences Campus, Cambridge, CB2 0QH, UK \\ ${ }^{3}$ SOLA Academy, Bernhard Gottlieb University Clinic of Dentistry, Sensengasse 2A, 1090 Vienna, Austria
}

Correspondence should be addressed to Roeland Jozef Gentil De Moor; roeland.demoor@ugent.be

Received 15 August 2014; Revised 13 November 2014; Accepted 13 November 2014

Academic Editor: Toni Zeinoun

Copyright ( 2015 Roeland Jozef Gentil De Moor et al. This is an open access article distributed under the Creative Commons Attribution License, which permits unrestricted use, distribution, and reproduction in any medium, provided the original work is properly cited.

\begin{abstract}
Light and heat increase the reactivity of hydrogen peroxide. There is no evidence that light activation (power bleaching with highintensity light) results in a more effective bleaching with a longer lasting effect with high concentrated hydrogen peroxide bleaching gels. Laser light differs from conventional light as it requires a laser-target interaction. The interaction takes place in the first instance in the bleaching gel. The second interaction has to be induced in the tooth, more specifically in the dentine. There is evidence that interaction exists with the bleaching gel: photothermal, photocatalytical, and photochemical interactions are described. The reactivity of the gel is increased by adding photocatalyst of photosensitizers. Direct and effective photobleaching, that is, a direct interaction with the colour molecules in the dentine, however, is only possible with the argon (488 and $415 \mathrm{~nm}$ ) and KTP laser $(532 \mathrm{~nm})$. A number of risks have been described such as heat generation. Nd:YAG and especially high power diode lasers present a risk with intrapulpal temperature elevation up to $22^{\circ} \mathrm{C}$. Hypersensitivity is regularly encountered, being it of temporary occurrence except for a number of diode wavelengths and the Nd:YAG. The tooth surface remains intact after laser bleaching. At present, KTP laser is the most efficient dental bleaching wavelength.
\end{abstract}

\section{Introduction}

Heating hydrogen peroxide (HP) results in an acceleration of its decomposition and oxidant-free radical formation [1]. Therefore, the dental bleaching process can be accelerated by additional heat activation. One of the activation methods resulting in an increase of the temperature in the bleaching gel is power bleaching with high-intensity light [2]

The effectiveness of this method for vital tooth bleaching has been demonstrated in animal studies, clinical studies and reports, and a number of reviews [3-6]. Side effects for the tooth, that is, alteration of the enamel surface, posttreatment, and pulp sensitivity, have been suggested and investigated [4, $5,7,8]$.

Potential adverse effects on enamel were primarily investigated in vitro using extracted human and bovine teeth.
Reports on the effects of light-activated systems were divergent, which was also the case for conventional in-office bleaching techniques. On the one hand, changes in microhardness, the presence of porosities, changes in surface roughness, a reduction in fracture toughness, alteration of the calcium/phosphate ratio, erosion, decrease in abrasion resistance, and the formation of depressions were reported. The enamel surface changes varied mostly with the bleaching products used, especially high concentrations of hydrogen peroxide; that is, $30-35 \%(\mathrm{w} / \mathrm{w})$ and $35 \%(\mathrm{w} / \mathrm{w})$ carbamide peroxide (CPO) (11-12\% HP) could have a damaging effect, whereas low concentrations $10 \%$ or $16 \%$ CPO $(w / w)(3-5 \%$ HP) had no effect [8]. On the other hand, rehardening of porous enamel as a result of saliva ion reprecipitation has been described. Although remineralisation due to the saliva 
may be responsible for a gradual mineral rebuild-up, full repair of the enamel is not established due to a degradation of the organic matrix [8]. To date, nevertheless, no clinical adverse effects of power bleaching on enamel have been reported.

Sensitivity after bleaching is higher when HP is combined with thermal activation [4-9]. Diverging results once again have been published regarding the effect of power bleaching on the pulp [4-9]. Also for this topic there is a lack of in vivo studies and there are no studies evaluating long-term effects of HP exposure on dental pulp.

An intrapulpal temperature increase of $5.5^{\circ} \mathrm{C}$ is nowadays regarded as the threshold value, which should not be exceeded to avoid irreversible pulp damage [10]. It appears that temperature during light-activated bleaching is in general under control, especially due to the presence of a bleaching $[4,10]$.

\section{Aim}

At present, there is no review on the efficiency of laser activated bleaching and its effect on the tooth (enamel and pulp). The aim of this review is therefore to evaluate the influence of the temperature rise during laser bleaching on the pulp, the postoperative sensitivity, and eventual enamel alterations. The efficiency is evaluated on the basis of the colour change in vitro and in vivo.

\section{Methods and Materials}

The electronic literature search included the databases PubMed and Web of Science for manuscripts published with full journal reference from January 1950 to November 2014. All languages were accepted provided there was an abstract in English. The following MeSH terms and key words were used: "lasers" AND "tooth bleaching," "lasers" AND "tooth discoloration," "tooth bleaching" OR "teeth bleaching" AND (argon laser OR diode laser OR KTP laser OR Nd:YAG laser OR Er:YAG laser OR Er, Cr:YSGG laser OR carbon dioxide laser). Two reviewers (AD and BV) independently assessed abstracts and full-text articles. First the reviewers considered the abstracts as potentially relevant. Abstracts dealing with this topic but without access to full journal article were not taken into consideration. Case reports were included only when they exclusively reported observations which were not described in other publications. Then full articles were read. Both reviewers selected independently the same 71 full-text articles; that is, Cohen's kappa $=1.0$.

\section{Results}

4.1. Temperature Rise in the Pulp. Taking into account the subject of the present review both power intensity and wavelength of the light used during the bleaching procedure must be taken into consideration [11]. An overview of the changes in temperature in the pulp during laser dental bleaching is given in Table 1 .

4.1.1. $\mathrm{CO}_{2}$ Laser $(10,600 \mathrm{~nm})$. Luk et al. [12] reported that the use of a $\mathrm{CO}_{2}$ laser $(10,600 \mathrm{~nm})$ on teeth for bleaching purposes led to a temperature increase of 13.1 to $22.3^{\circ} \mathrm{C}$ with gel at the enamel surface and 6.9 to $16.6^{\circ} \mathrm{C}$ at the pulpal side of the dentine. Due to a lack of controlled clinical studies this wavelength was not approved for bleaching by the ADA [30]. At present this wavelength is no longer used for dental bleaching.

4.1.2. Nd:YAG $(1,064 \mathrm{~nm})$. Next to the $\mathrm{CO}_{2}$ laser, the highest temperature elevations in the pulp were registered with the $\mathrm{Nd}$ :YAG laser $(1,064 \mathrm{~nm})$ irrespective of the use of coloured bleaching gels (blue, red, and transparent) $[13,14]$.

4.1.3. Diode Lasers. High power diode lasers (784-980 nm) are also known to be able to rise the pulpal temperature and should be used in combination with a bleaching gel. An overview of the reported data is given in Table 1 .

Laser activation with a $830 \mathrm{~nm}$ diode laser $(30 \mathrm{~s}, 3 \mathrm{~W})$ without bleaching gel may result in a temperature increase of $16^{\circ} \mathrm{C}$ in the pulp chamber; when applying the gel during laser activation only $8.7^{\circ} \mathrm{C}$ temperature increase was recorded [10].

With a $915 \mathrm{~nm}$ diode laser, there was an increase of temperature with $26.7^{\circ} \mathrm{C}$ at $3 \mathrm{~W}-20 \mathrm{~s}$ and $12.2^{\circ} \mathrm{C}$ at $1.5 \mathrm{~W}$ $20 \mathrm{~s}$ [16]. In the same study temperature rise was lower after application of a bleaching gel; the decrease was product related: By White gel (By Dental, Pistoia, Italy) at $3 \mathrm{~W}$ resulted in a rise of $17.0^{\circ} \mathrm{C}$ and at $1.5 \mathrm{~W}$ of $7.6^{\circ} \mathrm{C}$ with Whiteness HP (FGM Produtos Odontológicos, Joinville, Brazil) it was $+25.6^{\circ} \mathrm{C}$ at $3 \mathrm{~W}$ and $+6.0^{\circ} \mathrm{C}$ at $1.5 \mathrm{~W}$. The bleaching gel thus acts as a selective absorber near the dental surface, preventing light penetration into the internal tooth structure. Apparently the composition of the gel is also important as the gel layer was $2 \mathrm{~mm}$ thick in both investigations.

An increase of $2.61^{\circ} \mathrm{C}$ with a diode laser $(810 \mathrm{~nm})(4 \mathrm{~W}$, $20 \mathrm{~s})$ and $1.86^{\circ} \mathrm{C}$ with an Er:YAG $(2,940 \mathrm{~nm})(40 \mathrm{~mJ}, 10 \mathrm{~Hz}$, $20 \mathrm{~s})$ was registered by Sari et al. [17]. The temperature in the gel, however, was $6.21^{\circ} \mathrm{C}$ for the diode and $20.11^{\circ} \mathrm{C}$ for Er:YAG.

The increase in the pulp chamber temperature with a diode laser $(830 \mathrm{~nm})$ used at $1 \mathrm{~W}-30 \mathrm{~s}$ is below the critical temperature increase of $5.5^{\circ} \mathrm{C}$ that is nowadays regarded as the threshold value and which should not be exceeded to prevent irreversible pulp damage [18]. In the same study the diode laser at $2 \mathrm{~W}-30 \mathrm{~s}$ resulted in a temperature increase up to $6.8^{\circ} \mathrm{C}$ and $8.7^{\circ} \mathrm{C}$ with $3 \mathrm{~W}-30 \mathrm{~s}$; the importance of use of the gel with appropriate thickness was emphasized by measurements of the temperature at the surface: $1 \mathrm{~W}$ resulted in $37^{\circ} \mathrm{C}, 2 \mathrm{~W}$ in $64.1^{\circ} \mathrm{C}$, and $3 \mathrm{~W}$ in $86.3^{\circ} \mathrm{C}$.

Similar findings were registered by Fornaini et al. [19] where an $808 \mathrm{~nm}$ diode at $2 \mathrm{~W}$ during $3 \times 30 \mathrm{~s}$ resulted in heating of the gel up to $43.1^{\circ} \mathrm{C}$ and at $4 \mathrm{~W}-3 \times 30 \mathrm{~s}$ up to $74.9^{\circ} \mathrm{C}$.

A temperature increase of $2-8^{\circ} \mathrm{C}$ and $4-12^{\circ} \mathrm{C}$ was observed when a $960 \mathrm{~nm}$ diode laser was used to activate Opalescence Xtra (Ultradent Products, South Jordan, UT, USA) and Opus White (Opus Dent, London, UK) for $0.9 \mathrm{~W}$ $60 \mathrm{~s}$ and $2 \mathrm{~W}-30 \mathrm{~s}$ [20].

A mean increase of $11.75^{\circ} \mathrm{C}$ in the pulp was seen with an $810 \mathrm{~nm}$ diode used at $10 \mathrm{~W}-15 \mathrm{~s}$ [22].

With a hydrogen peroxide bleaching agent, the mean maximum pulpal temperature rise was $2.95^{\circ} \mathrm{C}$ for a $\mathrm{LED}$, 
TABLE 1: Increase in temperature $\left({ }^{\circ} \mathrm{C}\right.$ ) in the pulp (without or with gel application) after exposure to laser light.

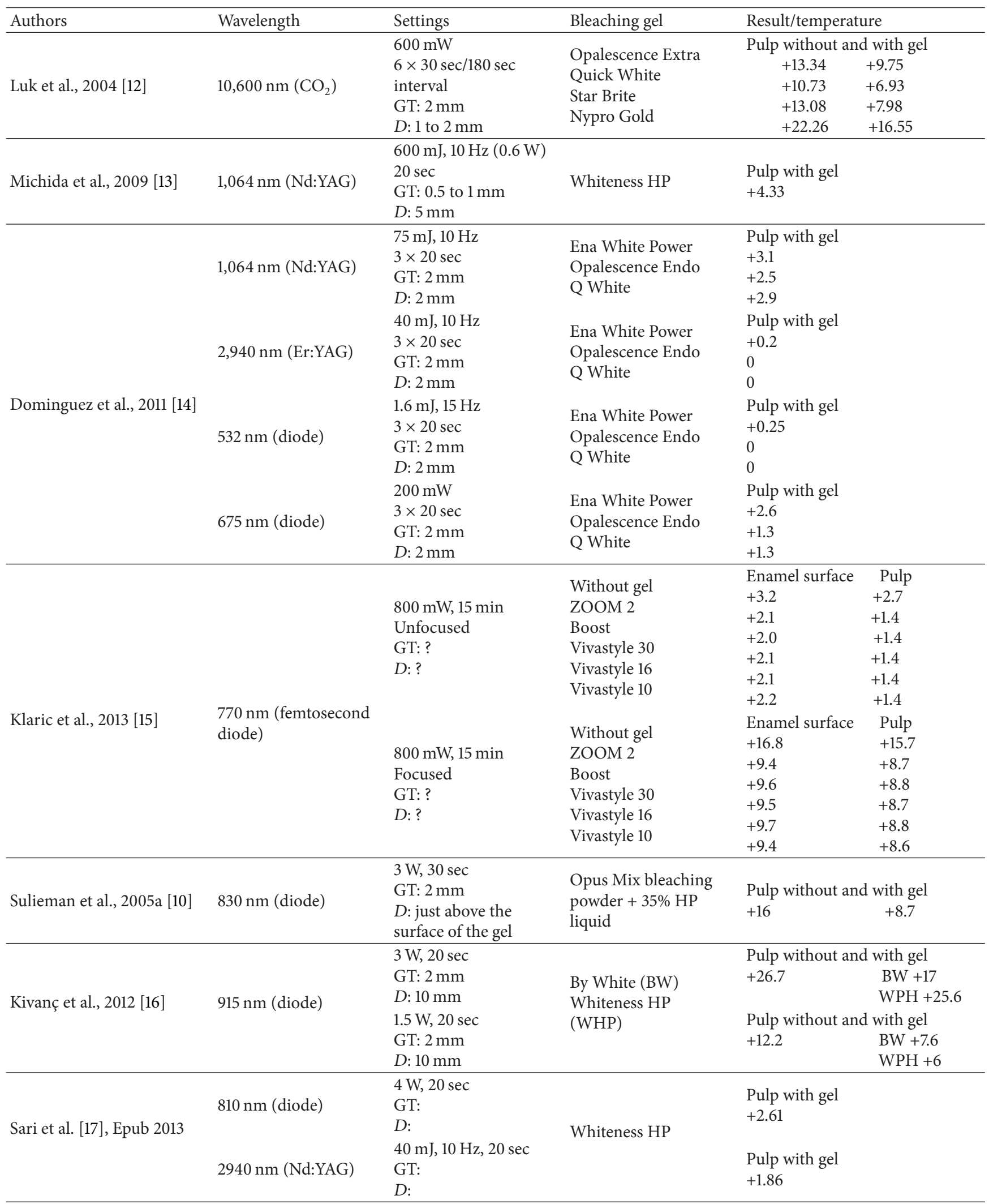


TABle 1: Continued.

\begin{tabular}{|c|c|c|c|c|c|c|}
\hline Authors & Wavelength & Settings & Bleaching gel & \multicolumn{3}{|c|}{ Result/temperature } \\
\hline Sulieman et al., 2006 [18] & $830 \mathrm{~nm}$ (diode) & $\begin{array}{l}30 \mathrm{sec} \\
3 \mathrm{~W} \\
2 \mathrm{~W} \\
1 \mathrm{~W} \\
\mathrm{GT}: 2 \mathrm{~mm} \\
D: \text { just above the } \\
\text { surface of the gel }\end{array}$ & $\begin{array}{l}\text { Opus Mix bleaching } \\
\text { powder }+35 \% \mathrm{HP} \\
\text { liquid }\end{array}$ & $\begin{array}{l}\text { Surface } \\
86.3 \\
64.1 \\
37\end{array}$ & $\begin{array}{c}\text { Pulp wi } \\
\quad \text { wit } \\
+11.6 \\
+7.7 \\
+5.23\end{array}$ & $\begin{array}{l}\text { hout and } \\
\text { gel } \\
+8.7 \\
+6.8 \\
+5.5\end{array}$ \\
\hline Fornaini et al., 2013 [19] & $808 \mathrm{~nm}$ (diode) & $\begin{array}{l}3 \times 30 \text { sec-rest time } \\
2 \mathrm{~min} \\
2 \mathrm{~W} \\
4 \mathrm{~W} \\
\mathrm{GT}: \\
D: \\
3 \times 30 \mathrm{sec} \text {-rest time } \\
2 \mathrm{~min} \\
2 \mathrm{~W} \\
4 \mathrm{~W} \\
\mathrm{GT}: \\
D:\end{array}$ & $\begin{array}{l}48 \mathrm{~g} \text { HP solution }+ \\
29 \text { g carbopol (HP } \\
\text { concentration } 27 \text { to } \\
35 \%)\end{array}$ & \multicolumn{3}{|c|}{$\begin{array}{l}\text { Peak gel temperature } \\
43.1 \\
74.9\end{array}$} \\
\hline Wetter et al., $2004[20,21]$ & $960 \mathrm{~nm}$ (diode) & $\begin{array}{l}0.9 \mathrm{~W}, 60 \mathrm{sec} \\
\mathrm{GT}: ? \\
D: 2 \mathrm{~mm} \\
2 \mathrm{~W}, 30 \mathrm{sec} \\
\mathrm{GT}: ? \\
D: 2 \mathrm{~mm}\end{array}$ & $\begin{array}{l}\text { Opalescence Xtra } \\
\text { (OPX) } \\
\text { Opus White (OW) }\end{array}$ & \multicolumn{3}{|c|}{$\begin{array}{l}\text { Pulp with gel } \\
\text { OPX }+8 \\
\text { OW comparable (8) } \\
\text { Pulp with gel } \\
\text { OPX }+12 \\
\text { OW comparable (8) }\end{array}$} \\
\hline Eldeniz et al., 2005 [22] & $810 \mathrm{~nm}$ (diode) & $\begin{array}{l}10 \mathrm{~W}, 15 \mathrm{sec} \\
\mathrm{GT}: \mathrm{OPX} ?-\mathrm{QS}: 1 \mathrm{~mm} \\
D: ?\end{array}$ & $\begin{array}{l}\text { Opalescence Xtra } \\
\text { (OPX) } \\
\text { Quasar Brite (QS) }\end{array}$ & \multicolumn{3}{|c|}{$\begin{array}{l}\text { Pulp with gel } \\
+11.75\end{array}$} \\
\hline \multirow[t]{2}{*}{ Zhang et al., 2007 [23] } & $980 \mathrm{~nm}$ (diode) & $\begin{array}{l}0.8 \mathrm{~W}, 30 \mathrm{sec} \\
\mathrm{GT}: 1 \mathrm{~mm} \\
D: 1 \mathrm{~mm}\end{array}$ & Hi Lite & \multicolumn{3}{|c|}{$\begin{array}{l}\text { Pulp with gel } \\
+7.72\end{array}$} \\
\hline & $532 \mathrm{~nm}(\mathrm{KTP})$ & $\begin{array}{l}1 \mathrm{~W}, 30 \mathrm{sec} \\
\mathrm{GT}: 1 \mathrm{~mm} \\
D: 1 \mathrm{~mm}\end{array}$ & & \multicolumn{3}{|c|}{$\begin{array}{l}\text { Pulp with gel } \\
3.76\end{array}$} \\
\hline Verheyen et al., 2006 [24] & $810 \mathrm{~nm}$ (diode) & $\begin{array}{l}1 \mathrm{~W}, 30 \mathrm{sec} \\
\mathrm{GT}: ? \\
D: ?\end{array}$ & $\begin{array}{l}\text { Opus White }(\mathrm{OW}) \\
\text { Ti-O2 gel (TO) }\end{array}$ & \multicolumn{3}{|c|}{$\begin{array}{l}\text { Pulp with gel } \\
\text { OW } 3 \\
\text { TO } 0\end{array}$} \\
\hline Goharkhay et al., 2009 [25] & $810 \mathrm{~nm}$ (diode) & $\begin{array}{l}1 \mathrm{~W}, 60 \mathrm{sec} \\
2 \mathrm{~W}, 60 \mathrm{sec} \\
\mathrm{GT}: ? \\
D: 6 \mathrm{~mm} \\
\end{array}$ & $\begin{array}{l}\text { Opalescence Xtra } \\
\text { Boost }\end{array}$ & \multicolumn{3}{|c|}{$\begin{array}{l}\text { Pulp without and with gel } \\
+5 \\
+9.6\end{array}$} \\
\hline Pleffken et al., 2012 [26] & $660 \mathrm{~nm}$ (diode) & $\begin{array}{l}50 \mathrm{~mW}, 3 \times 160 \mathrm{sec} \\
\mathrm{GT}: ? \\
D: 2 \mathrm{~mm}\end{array}$ & $\begin{array}{l}35 \% \text { experimental HP } \\
\text { gel }\end{array}$ & $\begin{array}{l}\text { In the gel } \\
+2.29\end{array}$ & \multicolumn{2}{|c|}{$\begin{array}{l}\text { Pulp with gel } \\
+1.8\end{array}$} \\
\hline Carrasco et al., 2008 [27] & $\begin{array}{l}\text { LED-laser } \\
470 / 790 \mathrm{~nm}\end{array}$ & $\begin{array}{l}40 \mathrm{~mW}, 3 \times 30 \mathrm{sec} \\
\mathrm{GT}: 1 \mathrm{~mm} \\
D: 5 \mathrm{~mm}\end{array}$ & Whiteness HP & \multicolumn{3}{|c|}{$\begin{array}{l}\text { Pulp without and with gel } \\
+0.35\end{array}$} \\
\hline Torres et al., 2008 [28] & $\begin{array}{l}\text { LED-laser } \\
470 / 784 \mathrm{~nm}\end{array}$ & $\begin{array}{l}120 \mathrm{~mW} \\
5 \times 40 \mathrm{secc} \\
\mathrm{GT}: 2 \mathrm{~mm} \\
D: 5 \mathrm{~mm}\end{array}$ & Whiteform Perox Red & \multicolumn{3}{|c|}{$\begin{array}{l}\text { Critical temperature rise of } 5.5^{\circ} \mathrm{C} \\
\text { not reached }\end{array}$} \\
\hline Coutinho et al., 2009 [29] & $\begin{array}{l}\text { LED/laser } \\
\text { 470/795 nm } \\
\text { LED/laser } \\
\text { 530/795 nm }\end{array}$ & $\begin{array}{l}120 \mathrm{~mW}, 3 \times 60 \mathrm{sec} \\
20 \mathrm{~mW}, 3 \times 60 \mathrm{sec}\end{array}$ & Whiteness HP & $\begin{array}{l}\text { Pulp with } \\
\text { Incisor } \\
\text { Canine } \\
\text { Premolar } \\
\text { Incisor } \\
\text { Canine } \\
\text { Premolar }\end{array}$ & $\begin{array}{l}\text { gel } \\
+3.1 \\
+2.5 \\
+1.9 \\
+0.6 \\
+0.2 \\
+0.3 \\
\end{array}$ & \\
\hline
\end{tabular}

GT: gel thickness; $D$ : distance between light source and the bleaching gel. 
$3.76^{\circ} \mathrm{C}$ for a $\mathrm{KTP}$ laser $(1 \mathrm{~W}-30 \mathrm{~s})$, and $7.72^{\circ} \mathrm{C}$ for a $980 \mathrm{~nm}$ diode laser (0.8 W-30 s) [23].

With an output power of $1 \mathrm{~W}-30 \mathrm{~s}$ of an $810 \mathrm{~nm}$ diode laser, pulpal temperature increase was shown to be approximately $3^{\circ} \mathrm{C}$ with the Opus White gel (Opus Dent), whereas a $\mathrm{TiO}_{2}$ emulsion showed almost no temperature changes in the pulp [24].

A treatment protocol with intermittent irradiation of six times for $5 \mathrm{~s}$, with 5 breaks in between, at a power setting of less than $1 \mathrm{~W}$, with a $810 \mathrm{~nm}$ diode laser excluded thermal damage to the pulp, whereas the temperature at the surface was $5^{\circ} \mathrm{C}$. Irradiation at $2 \mathrm{~W}$ with the same protocol resulted in a temperature elevation of $9.6^{\circ} \mathrm{C}$ at the surface and $2.8^{\circ} \mathrm{C}$ in the pulp chamber [25].

The addition of colorants may help to provide a better absorption of high power diode laser light in the bleaching gel and less transmission towards the pulp chamber. Pleffken et al. [26] demonstrated that a low-intensity red diode laser $(660 \mathrm{~nm})(50 \mathrm{~mW}-3 \times 180 \mathrm{~s})$ with a green-coloured bleach gel resulted in not more than a $2.3^{\circ} \mathrm{C}$ temperature elevation in the pulp chamber.

It is clear that power and type (wavelength) of the light source influence temperature variation. Studies have shown that near-infrared lasers could improve the inflammatory response of the pulpal tissue, reducing pulp damage and relieving pain after the bleaching process [31]. Its use would diminish patients' sensitivity complaints after the procedure. In this respect $L E D$ devices were associated with diode lasers emitting in the near-infrared. According to Carrasco et al. [27] $470 / 790 \mathrm{~nm}(40 \mathrm{~mW}-3 \times 30 \mathrm{~s})$ temperature is under control. Other studies also demonstrated negligible temperature changes: $470 / 784 \mathrm{~nm}(120 \mathrm{~mW}-5 \times 40 \mathrm{~s})$ [28], $470 / 795 \mathrm{~nm}$ $(120 \mathrm{~mW}-3 \times 60 \mathrm{~s})$, and $530 / 795 \mathrm{~nm}(20 \mathrm{~mW} / 3 \times 60 \mathrm{~s}$ [29]). Moreover it appears that these combination types of light sources with low power density are not powerful enough to provide a better bleaching efficacy as compared to other light sources $[20,23,32]$.

A comparison between different laser wavelengths by Dominguez et al. [14] used as follows: that is, three bleaching gels (transparent, with blue dye, with red dye, composition of dye mentioned) exposed during 3 times for $20 \mathrm{sec}$ to the light source with a 9 min interval and an overall contact time of the gel with the tooth surface during $30 \mathrm{~min}$, demonstrated the following temperature effects in decreasing order: $N d: Y A G$ $(1064 \mathrm{~nm})$ (rise of $3.1^{\circ} \mathrm{C}$ in the pulp chamber) $>$ halogen lamp $(120 \mathrm{~nm})>$ low power diode $(675 \mathrm{~nm})>$ low power LED $(380-530 \mathrm{~nm})>2 \omega N d: Y A G(532 \mathrm{~nm})>\operatorname{Er}: Y A G(2940 \mathrm{~nm})$. These findings coincided with the findings of Torres et al. [28] (halogen versus diode 470/784 nm) and Carrasco et al. [27] (halogen versus diode 470/790 nm versus LED).

In a study of Klaric et al. [15] a comparison was made between ZOOM2 (350-400 nm) during $15 \mathrm{~min}$, LED $(405 \mathrm{~nm})$ during $30 \mathrm{~min}$, OLED (organic light emitting diode) (400-760 $\mathrm{nm})$ during $30 \mathrm{~min}$, and a femtosecond laser (770 nm) (Millenia, Spectra Physics, USA) during $30 \mathrm{~min}$ : ZOOM2 resulted in high temperature elevations $\left(+15.4^{\circ} \mathrm{C}\right)$ in the pulp whereas elevations were $+21.1^{\circ} \mathrm{C}$ without use of bleaching gel; the femtosecond laser focused: $+15.7^{\circ} \mathrm{C}$ without gel and $+8.7^{\circ} \mathrm{C}$ with gel; the femtosecond laser unfocused: $+2.7^{\circ} \mathrm{C}$ without gel and $+1.4^{\circ} \mathrm{C}$ unfocused. In this respect it has also to be mentioned that the mechanism of heat conversion depends directly on the tissue constituents and the irradiation wavelength used. It is known that the tooth absorption coefficient is lower for the wavelength range 400 $<\lambda<500 \mathrm{~nm}$; thus scattering predominates over absorption at these wavelengths.

Er:YAG $(2,940 \mathrm{~nm})$. In a study of Kivanç et al. [16] temperature increase in the pulp was neglectable. A very low temperature rise of $1.86^{\circ} \mathrm{C}$ was registered by Sari et al. [17].

$\operatorname{KTP}(532 \mathrm{~nm})$. Using the green light of the KTP to irradiate a red coloured bleaching gel resulted in a temperature of $32^{\circ} \mathrm{C}$ at $2 \mathrm{~W}$ during $30 \mathrm{sec}$ and $45.1^{\circ} \mathrm{C}$ at $4 \mathrm{~W}$ during $30 \mathrm{sec}$ [19].

With a hydrogen peroxide bleaching agent, the mean maximum pulpal temperature rise was $2.95^{\circ} \mathrm{C}$ for a LED, $3.76^{\circ} \mathrm{C}$ for a KTP laser, and $7.72^{\circ} \mathrm{C}$ for a diode laser [23].

4.2. Influence on the Characteristics and Material Properties of the Teeth. The aim of a bleaching procedure is to bleach the tooth without morphological and chemical changes. However, side effects after power bleaching in the enamel such as changes in microhardness, the presence of porosities, changes in surface roughness, a reduction in fracture toughness, alteration of the calcium/phosphate ratio, erosion, decrease in abrasion resistance, and the formation of depressions were reported. Weakening of enamel structure by oxidation of organic or inorganic elements is considered to be the main cause [33].

4.2.1. Morphological Analysis. Morphological analysis showed slight changes with the diode laser $(970 \mathrm{~nm})$ and the LED/laser $(467 \mathrm{~nm} / 790 \mathrm{~nm})$ [34]. Surface effects were unrelated to the $\mathrm{pH}$ of the high concentration HP bleaching gels with laser activation and referred more to a better or lesser absorption of the laser light by the bleaching gel. Chromophores and the use of $\mathrm{TiO}_{2}$ appeared to be favourable for the maintenance of an intact tooth surface [25]. No significant effects on the morphology of the enamel surface after laser bleaching with diode laser, KTP, Nd:YAG, and Er:YAG were observed by Dominguez et al. [14].

4.2.2. Mineral Content. FT-RS results showed a decreased mineral content after bleaching procedures with and without light activation and with 35\% HP-based bleaching agents. The use of a LED/laser $(470 \mathrm{~nm} / 810-830 \mathrm{~nm})$ resulted in comparable calcium loss as compared to the non-lightactivated bleach gels for 2 of 3 brands. Exposing Pola Office (Southern Dental Industries, Sao Paulo, SP, Brazil) to the LED/laser did not result in a significant calcium loss [35]. An explanation for this difference was not given.

No significant differences in levels of calcium and phosphorus were seen after 470/830 nm LED/laser bleaching [36].

In a study of Cesar et al. [37] with 35\% HP-based bleaching agents activated with a LED/laser $(465.5 \mathrm{~nm} / 790 \mathrm{~nm})$, FT-Raman spectroscopy data showed no significant chemical changes in the inorganic components for the tested 
groups. Carbonate and phosphate area peaks were not significantly changed. Whiteness HP Maxx (FGM Produtos Odontológicos Ltda., Santa Catarina, Brazil) and Opalescence Xtra (Ultradent Products) were also tested in the study of Berger et al. [35]. There was a significant reduction of the dental organics associated with type I collagen vibration only in the group of Whiteform-Perox Red gel (Formula \& Acao, Sao Paulo, SP, Brazil). This means that there is a difference between both studies. Total contact time of the gels was identical, that is, 3 consecutive gel applications for $10 \mathrm{~min}$. Irradiation protocols, however, differed: in Berger et al. [35], there was a bleaching gel left on third molars undisturbed for $1 \mathrm{~min}$ and then irradiated for $2 \mathrm{~min}$; the light irradiation was repeated 3 times with a 1 min interval between radiations; in Cesar et al. [37] there was photoactivation of the gel for $30 \mathrm{sec}$ for a total of $10 \mathrm{~min}$ of application on bovine teeth. Moreover, similar differences in findings were also observed with non-light-activated high concentration HP bleaching gels. Whether the differences found for the present two studies are related just to the bleaching protocol is not clear yet; in fact differences in oxidizing potential (stronger), stronger concentrations, longer treatment times, and lower $\mathrm{pH}$ of bleaching gels could be responsible for the changes found in the studies [37].

In a study with bovine teeth using a low power diode laser $(740 \mathrm{~nm}, 300 \mathrm{~mW}$ power) it was seen that the enamel crystallinity was dramatically decreased by a bleaching treatment without laser irradiation. However, crystallinity increased as laser irradiation time increased. It was concluded that professional bleaching treatment with HP combined with a diode laser irradiation not only improves the bleaching effect but also protects against the change of enamel structure compared with the bleaching treatment without laser irradiation [38].

TEM analysis showed the formation of a new phase $2 \mu \mathrm{m}$ thick layer. The assumption was also made that the chemical property of the bleaching gel could have been changed through exposure to laser irradiation. It can also be that this phenomenon accounts for bovine teeth where the enamel contains significantly more interprismatic organic material compared to human enamel even though its structure and compositions are very similar to those of human enamel.

4.2.3. Microhardness. The microhardness test is suitable for determining small changes in surface that demonstrated the effect of bleaching products on enamel [39].

A comparison between argon laser $(488 \mathrm{~nm}, 200 \mathrm{~mW}$, $30 \mathrm{sec}$ irradiation and 4-minute intervals during $40 \mathrm{~min}$ ) and halogen lamp-based photopolymerizer ( $2 \mathrm{~min}$ and $240 \mathrm{~mW}$, and 4-minute intervals during $40 \mathrm{~min}$ ) did not result in differences with the control group using 35\% and 37\% CP [37].

Zhang et al. [23] showed no differences between the control (35\% HP) and KTP (1 W, $30 \mathrm{sec}$, energy density (ED) $\left.13.33 \mathrm{~J} / \mathrm{cm}^{2}\right)$, diode $980 \mathrm{~nm}\left(0.8 \mathrm{~W}, 30 \mathrm{sec}, \mathrm{ED}: 13.33 \mathrm{~J} / \mathrm{cm}^{2}\right)$, and blue LED composite curing lamp $(470 \mathrm{~nm}, 30 \mathrm{~s}$, ED: $\left.12.6 \mathrm{~J} / \mathrm{cm}^{2}\right)$ experimental groups. Diode laser $(830 \mathrm{~nm})$ irradiation ( 3 times, $30 \mathrm{sec}$ irradiation at $1.4 \mathrm{~W}$ of newly placed) of the $35 \% \mathrm{HP}$ gel associated or not with ACP did not interfere with microhardness [40].

Reduction in microhardness was found after bleaching with a LED/laser $(470 / 830 \mathrm{~nm}$, light intensity of $200 \mathrm{~mW}$, 1 min laser activation of the gel, followed by 2 -minute rest; this procedure was repeated 3 times), which recovered to baseline values after 1 week of immersion in artificial saliva [36].

4.2.4. Enamel Permeability. Higher permeability of the enamel surface after a bleaching procedure with a LED/laser (470-790 nm) and QTH light as compared to a control (35\% HP) was reported; there were no significant differences between the two bleach protocols [41].

Bleaching with a $470 / 830 \mathrm{~nm}$ LED/laser did not show any statistical difference with baseline with regard to dye penetration [36].

4.2.5. Caries Susceptibility of Bleached Enamel. In-office laser bleaching with a LED/laser $(830 \mathrm{~nm})$ does not result in a higher susceptibility for caries lesions [42].

4.2.6. Fracture Strength. Araujo et al. [43] showed that a LED/laser $(465.5 \mathrm{~nm} / 790 \mathrm{~nm})$ did not influence the fracture strength of enamel after light-activated bleaching.

4.2.7. Bonding to Bleached Enamel. Bonding to intracoronally light-activated bleached dentine should be performed at least 10 days after a bleaching procedure with a LED/laser $(465.5 \mathrm{~nm} / 790 \mathrm{~nm})$ [44]. A time interval of 2 to 3 weeks was advocated for applying silorane-based composite restorations of methacrylate based composites after bleaching with an $815 \mathrm{~nm}$ diode laser [45]. A week interval after bleaching with an $815 \mathrm{~nm}$ diode and 430-490 $\mathrm{nm}$ blue LED showed statistically significantly lower shear bond values as compared to the control and bleaching with QTH light $(380-520 \mathrm{~nm})$ [44]. The failure mode in this latter study was adhesive for the diode laser (80\%) and the LED (70\%); for both the control group and the QTH lamp the failure mode was mixed (adhesive and cohesive) (70\%).

\subsection{Hypersensitivity}

4.3.1. Diodes and LED/Lasers (Diodes). Sensitivity is described by some as common with the diode laser. Bleaching with a diode laser $(810 \mathrm{~nm}, 35 \% \mathrm{HP})$ just reached the level that can be tolerated by the patient [46]. Comparing a diode laser ( $810 \mathrm{~nm}, 37 \% \mathrm{HP}$ ) with PAC activation (400$490 \mathrm{~nm}, 35 \% \mathrm{HP})$, LED activation (400-500 nm, 38\% HP) and no light activation (38\% $\mathrm{HP}$ ) resulted in the lowest sensitivity for the diode laser [47].

In the study of Kossatz et al. [48] 53.3\% of the participants had sensitivity even 24 hours after laser bleaching with a LED/laser unit $(470 \mathrm{~nm} / 830 \mathrm{~nm}, 35 \% \mathrm{HP})$ with a protocol of gel activation during $1 \mathrm{~min}$, leaving the gel undisturbed during $2 \mathrm{~min}$ and repeating this protocol 3 times and the in-office bleaching agent was refreshed every 15 minutes during a 45-minute application period. Immediate sensitivity was also scored in the study of Mondelli et al. [47] with a LED/laser (470 nm/810 nm, 35\% HP). Sensitivity decreased 
after 24 hours to return to normal after 7 days. There were no differences between in-office gels (light- and non-lightactivated).

An increased expression of substance $\mathrm{P}$ was seen when a LED laser (470 nm, 35\% HP) was used [49].

More recent studies demonstrated that sensitivity was generated independently of the light sources used: Almeida et al. [50] with a LED/laser at $425-480 / 810 \mathrm{~nm}$, Martin et al. [51] with a LED/laser at $450 / 808 \mathrm{~nm}$, and Moncada et al. [52] with a LED/laser at $425-480 / 808-830 \mathrm{~nm}$. The latter two studies demonstrated a higher impact of the increase in concentration of bleaching agents on tooth sensitivity; treatment with carbamide peroxide generated also lower sensitivity than treatment with HP independently of the light sources.

A comparison between all these studies is difficult and impossible because each investigation is different, that is, different protocols. Moreover, complete basic information, that is, power settings, gel thickness, distance between gel, and light source, is not provided in the listed studies.

4.3.2. Nd:YAG. When using the Nd:YAG laser $(1,064 \mathrm{~nm}$, $35 \% \mathrm{HP}$ ) for laser bleaching at $4 \mathrm{~W}, 10 \mathrm{~Hz}, 320 \mu$ s pulse duration, and an energy density of $1.4 \mathrm{~J} / \mathrm{cm}^{2}$ in association with a red coloured gel, no enhancement of the bleaching success was found [52]. There was no reduction in hypersensitivity, as can be seen when Nd:YAG is used for the treatment of dentinal hypersensitivity. Only $20 \%$ of the patients in this study had a pain-free treatment with the Nd:YAG laser. The remaining patients felt the development of warmth to the point of pain, even a few days after laser treatment. The authors concluded to query the appliance of Nd:YAG laser irradiation for in-office bleaching.

\subsection{Laser Bleaching: Tooth Colour Change and Efficiency}

4.4.1. Colour Change In Vitro. A comparison based on analysis of photoreflectance spectra between the use of an argon laser $(488 \mathrm{~nm})$ and halogen lamp with $35 \%$ and $37 \%$ CPO gave better results for the $35 \%$ CPO gel. Halogen was as effective as argon laser with 35\% CPO; argon was more effective than halogen for the $37 \%$ CPO [32]. A comparison between LED/diode laser (450-500 nm/830 nm), argon $(488 \mathrm{~nm})$, PAC $(440-550 \mathrm{~nm})$, and halogen $(350-500 \mathrm{~nm})$ showed better results for a 35\% HP than for 37\% CBP. A decrease in reflectance values was seen after 30 days; no difference was observed in bleaching efficiency between activated and nonactivated bleaching gels with high HP concentrations [53].

In a study comparing KTP $(532 \mathrm{~nm}, 35 \% \mathrm{HP})$ with a diode laser ( $810 \mathrm{~nm}, 38 \% \mathrm{HP}, 37 \% \mathrm{HP}$, and 35\% HP) [25] improved changes in brightness of up to ten steps on the Vitapan classical shade guide were detected. Prerequisites, however, were a perfect match of the chosen wavelength and the bleaching gel. A neutral and basic $\mathrm{pH}$ of the bleaching gel is also advantageous. The higher bleaching power of KTP as compared to an $808 \mathrm{~nm}$ diode laser was confirmed by Fornaini et al. [19].
Diode laser activation ( $808 \mathrm{~nm}, 35 \% \mathrm{HP}$ ) of the bleaching agent was not more effective than the halogen lamp for bleaching root canal treated primary molars [54], safer for $T^{\circ}$ development. Activation of a 35\% HP bleaching gel by diode laser $(830 \mathrm{~nm}, 35 \% \mathrm{HP})$ as well as a xenon halogen light, a plasma arc lamp, and halogen light did not differ in result from the use of the same gel without light activation [55]. A comparison between a $980 \mathrm{~nm}$ diode laser and a xenon arc lamp (430-500 nm) used with a $35 \%$ HP bleaching gel showed that there was an increase in colour saturation $\left(\Delta C^{*}\right)$ of $3-32 \%$ and a change in whiteness $\left(\Delta L^{*}\right)$ of $0-8 \%$ [14]. The highest efficacy was achieved with the diode laser at $2 \mathrm{~W}$, the lowest with the diode laser at $0.9 \mathrm{~W}$. However, due to the risk of higher temperature development, the authors considered the xenon lamp as the safest. A comparison between a diode laser $(808 \mathrm{~nm})$ and LED $(471 \mathrm{~nm})$ demonstrated significant comparable change in chroma for the two $35 \% \mathrm{HP}$ bleach gels investigated and the light sources. There was also a significant change in lightness for all test conditions, but the diode scored significantly best with the Whiteness HP bleaching agents (FGM Produtos Odontológicos, Joinville, Brazil) than with Opalescence Xtra (Ultradent Products) [21].

A comparison between different laser wavelengths by Dominguez et al. [14] demonstrated that the source of irradiation was more relevant than the bleaching agent for efficient tooth bleaching. They exposed three 35\% HP bleaching gels (transparent, with blue dye, and with red dye, composition of dye mentioned) during 3 times for $20 \mathrm{sec}$ to the light source with a 9 min interval; contact time of the gel with the tooth surface was $30 \mathrm{~min}$. LED (380-530 nm, low power), halogen lamp $(120 \mathrm{~nm})$, and diode $(675 \mathrm{~nm}$, low power) produced greater colour changes than the rest of the light sources: Nd:YAG $(1064 \mathrm{~nm})$, Er:YAG $(2940 \mathrm{~nm})$, and $2 \omega \mathrm{Nd}$ :YAG $(532 \mathrm{~nm})$. The mean improvement in tooth whiteness with the latter three wavelengths is in the same order as without photoactivation. It is thus the question if these wavelengths are really suited for bleaching gel activation. These findings differ from other studies where the effect of an Nd:YAG was comparable with a halogen light [56], and the effect of KTP was better as compared to diode $(980 \mathrm{~nm})$ and blue LED $(470 \mathrm{~nm})$ [23], but these chromophores were chosen as a function of the wavelength used (Nd:YAG: Q-switch dye with maximum absorption at $1051 \mathrm{~nm}$ ) (KTP: sulphorhodamine B with maximum absorption at $542.8 \mathrm{~nm}$ ).

4.4.2. Clinical Efficacy. When the Nd:YAG laser (35\% HP) was used for bleaching, Strobl et al. [57] found no supportive influence of the laser radiation on the bleaching. The authors registered a change in the colour of the bleach gel after laser activation, being a result of the increased formation of chemicals radicals, but could not explain why this does not translate in improved clinical result.

The use of a low-intensity red diode laser $(660 \mathrm{~nm}, 35 \%$ $\mathrm{HP}$ ) with a green-coloured bleach gel resulted in a change of colour ( $\Delta E$ was increased from 5.4 to 7.2 after 1 week) [26].

Overall shade change values recorded by spectrophotometer reading expressed as $\Delta L, \Delta a, \Delta b$, and $\Delta E$ were significantly higher for diode laser ( $810 \mathrm{~nm}, 37 \% \mathrm{HP}$ ) bleaching than PAC activation (400-490 nm, 35\% HP), LED activation 
(400-500 nm, 38\% HP), and no light activation (38\% HP), although shade guide evaluations did not exhibit any differences [58]. One session of $20 \mathrm{~min}$ of in-office bleaching with or LED ( $470 \mathrm{~nm}, 35 \% \mathrm{HP}$ ) (3 min irradiation to each group of 3 teeth) or diode laser ( $808 \mathrm{~nm}, 35 \% \mathrm{HP}$ ) (30 sec irradiation per tooth) as initiator followed by $10 \% \mathrm{CP}$ home-bleaching during 7 days was not more effective than 10\% CP homebleaching alone during 14 days [59]. Bleaching with an $841 \mathrm{~nm}$ diode laser and 35\% HP showed greater shade improvement for teeth with hue A shade than those with hue $\mathrm{C}$ and $\mathrm{D}$. The bleaching process is better in younger patients and gender is not a factor that affects the bleaching process [46].

LED/laser at $470 \mathrm{~nm}$ (one wavelength mentioned) did not show any improvement in bleaching result for the treatment of vital teeth as compared to halogen light, LED, and nonlight-activated 35\% HP. All treatments resulted in an increase of $\Delta E$ (best score for the non-light-activated protocol), which was maintained for 1 month and then dropped at 6 months (from on average 8 at 1 month to 7.7 at 6 months for the light-activated systems and from 9.8 to 8.8 for the nonlight-activated group) [60] but also meaning that there was only a slight colour rebound. LED/laser $(470 \mathrm{~nm} / 808 \mathrm{~nm})$ did not improve the in-office bleaching results with 35\% HP as compared to QTH (quartz-tungsten-halogen) light and at home bleaching with $10 \%$ CPO [50]. A change in colour was registered for all protocols, which was maintained over a 6month period [50]. In another investigation LED/laser (450$500 \mathrm{~nm} / 830 \mathrm{~nm}, 35 \% \mathrm{HP}$ ) did not improve the bleaching effectiveness during any phase of the study [27] as compared to two different LEDs (450-500 nm at $164 \mathrm{~mW}$ and $430-$ $490 \mathrm{~nm}$ at $88 \mathrm{~mW}$, with $35 \% \mathrm{HP}$ ) and a halogen lamp (350$500 \mathrm{~nm}$ at $470 \mathrm{~mW}, 35 \% \mathrm{HP}$ ) and additional sessions did not improve the results obtained in the first session. Change of color was registered for all systems. In a study by Mondelli et al. [47] in-office bleaching (35\% and 38\% HP) with and without activation with a LED/laser $(470 \mathrm{~nm} / 810 \mathrm{~nm})$ was compared with home bleaching (15\% CPO). All techniques and bleaching agents were effective. There was no difference in $\Delta E$ between non-light- and light-activated in-office treatment. The initial increase in $\Delta E$ decreased over a time period of 24 months (from on average 7.8 to 2 for the high concentration HP, from 9.8 to 3.3 for the home bleaching procedure with $15 \% \mathrm{CPO}$ ).

Visible green light KTP laser (532 nm, 35\% HP) combined with sulphorhodamine B-photosensitizer bleaching gel activated for $30 \mathrm{sec}$ at $1 \mathrm{~W}$ provided a clinically useful improvement in tooth shade in teeth with tetracycline discolorations $[61,62]$. KTP was more efficient than a $810 \mathrm{~nm}$ diode laser for the removal of discolourations due to red fruits, tea, and coffee [63]. KTP is more efficient for tetracycline discolouration than a high powered green LED for the bleaching of tetracycline-stained dentine [64].

\section{Discussion}

Light sources are marketed with the idea that light plays a significant role in tooth bleaching as catalyst for the ionization of HP in the bleaching gel and increasing the bleaching effect. Studies on light sources with incoherent light sources have produced contradictory results, but the following conclusions were drawn on the basis of a systematic review: (1) both light-activated and non-light-activated systems showed similar immediate and short-term bleaching effects when high concentrations of HP (25-35\%) were used as bleaching gel; (2) there is limited evidence that a light-activated system produced better immediate bleaching efficacy than when non-light-activated systems with a lower concentration of HP (15-20\%) were used [9].

Two key factors determining overall tooth bleaching efficacy from peroxide containing gels are the concentration of the HP and the duration of application.

For as far as the specific topic of laser activated bleaching is concerned, contradictory results are found as was also seen with conventional bleaching procedure using high hydrogen peroxide concentrations. In addition, the number of laser activated bleaching studies is limited as compared to the literature on light-activated bleaching. Comparisons between the effects of different wavelengths are difficult to make: (1) for laser bleaching absorption in the bleaching gel is aimed to drive the ionization of the HP; this depends on the specific wavelength needed to directly photolyze or photooxidate the chromophores in the dentine; (2) the chosen wavelength has to coincide with the absorption peak of chromophores or photocatalysers in the bleaching gel (if present) in order to catalyse the ionisation of the hydrogen peroxide and to drive the photolysis; (3) there is the heterogeneity of the heating temperature of the gel, that is, the photothermal effect which is even so influenced not only by the wavelength, but also by the specific power settings; (4) because of the previously mentioned heterogeneity of the laser settings, seen when a specific laser wavelength is considered, the bleaching gel must be developed taking into account the specific laser wavelength; (5) in addition, power density or energy density (fluence) of the laser beam is important; temporal characteristics of the laser beam are to be considered such as continuous versus pulsed delivery and consequently the pulse rate and the pulse duration; other variables that relate to differences in the method of energy transfer such as contact versus noncontact delivery mode, focused versus unfocused, and beam diameter have also to be considered. Last but not least there are the differences in the exposure time of the gel to the laser light and the specific bleaching protocol (e.g., one exposure or consecutive exposures of a fresh bleaching gel do also contribute to the heterogeneous data).

In general, laser bleaching is performed with a hand piece or a fibre in noncontact mode, unfocused, and with continuous emission. Regarding the power or energy, high power lasers are generally used, except when bleaching is performed with the argon laser (488 or $514.5 \mathrm{~nm}$ ) or with a 660,675 , or $740 \mathrm{~nm}$ diode laser.

All studies selected for this survey on laser bleaching have in common the fact that a high HP concentrated bleaching gel is used ( 35 to $38 \% \mathrm{HP}$ and 35 or $37 \% \mathrm{CP}$, i.e., 12 to $13 \%$ $\mathrm{HP})$. None of the clinical studies used low concentrations of HP. For HP concentrations of $6 \%$, it is known that light activation produced better immediate bleaching effects [9]. The EU Council Directive 2011/84/EU of September 20, 2011 [65], restricts the use of bleaching and bleaching products: 
only dentists may use products for tooth bleaching and only bleaching products that contain or release between $0.1 \%$ and $6 \% \mathrm{HP}$ and products for tooth bleaching and bleaching that contain or release up to $0.1 \%$ HP are available as over-thecounter products. Products with HP concentrations over $6 \%$ are prohibited as cosmetics. This clearly means (1) that products containing or releasing more than $6 \%$ are prohibited for dental bleaching and (2) that dental bleaching is not considered as a medical action but only as cosmetical and hence nonhealing procedure. Information on laser activation of bleaching products up to $6 \%$ with lasers has not been published.

A number of wavelengths can be considered as not recommended for laser bleaching: Nd:YAG (1,064 nm), Er:YAG $(2,940 \mathrm{~nm})$, and $\mathrm{CO}_{2}(10,600 \mathrm{~nm})$. The effect of these laser wavelengths is purely based on heating of the bleaching gel (Nd:YAG) or should only be restricted to heating of the bleaching gel (Er:YAG and $\mathrm{CO}_{2}$ : care has to be taken not to remove tooth substance with Er:YAG and $\mathrm{CO}_{2}$ because both wavelengths are well absorbed by water and hydroxylapatite which might result in superficial ablation of tooth substance). Although the $\mathrm{CO}_{2}$-laser received an FDA approval for bleaching, the ADA soon after recommended not to use this wavelength for bleaching.

From all bleaching wavelengths the diode wavelengths have been most extensively investigated. A large range of diode wavelengths are used as laser bleaching wavelengths. These near-infrared lasers are used at low power or at high power. Both low power and high power diode lasers do not result in an enhanced bleaching efficacy when compared to non-light-activated bleaching with high HP concentrations. The question is even if low power diodes aid in the activation of the bleaching gel. Care, however, has to be taken with the high power diodes so as not to heat the bleaching gel at a level at which thermal damage of the pulp might occur.

Another key factor to increase the rate of the chemical reaction is to increase the temperature, where a rise of $10^{\circ} \mathrm{C}$ can double the reaction rate. On the one hand the thickness of the bleaching gel layer is important to ensure that the laser light can pass through this layer. The distance between the handpiece or fibre end and the gel is important when the energy is considered. Laser interaction is not limited to the gel alone and laser light has also to interact with the discolouration in the tooth.

Adding chromophores, chosen in accordance to the absorption peak of the gel, acts as a selective absorber near the dental surface, preventing light penetration into the internal tooth structure. The colour of the gel is important as it influences the final temperature, since different light sources have different emission wavelengths and the absorption peak changes following gel colour. Also here the question is if the dyes added for photoactivation of the gel with diode lasers are helpful in activating the bleaching gel. With high power diode lasers, irrespective of the thickness of the bleaching gel, care has to be taken still so as not to extensively dehydrate the enamel due to the temperature effect.

Recently LED devices were associated with diode lasers emitting in the near-infrared, which, with appropriate energy density, are being used to desensitize the teeth under bleaching $[24,66]$. These studies demonstrated that nearinfrared lasers could reduce the inflammatory response of the pulpal tissue, reducing pulp damage and relieving pain after the bleaching process. The use of these devices (so-called LED lasers), however, did not result in any increased bleaching efficacy. Thus the question is to what extent these low power diodes are of help in the bleaching process.

Light-activated systems were found to increase the occurrence of severity of tooth sensitivity [9]. The light source itself can increase pulpal temperature leading to increased tooth sensitivity [66]. The latter was also encountered with diode lasers $[46,48]$ and Nd:YAG $[13,14,52]$. For both wavelengths laser light is transmitted through the bleaching gel in combination with a heating of the gel, irrespective of the thickness of the gel leading to tooth sensitivity $[10,14$, $16,19]$. An additional explanation is also that laser activated bleaching may increase the expression of substance $\mathrm{P}$ in the human dental pulp $[58,67]$.

Taking into account all different wavelengths used for laser activated bleaching, the KTP laser when used at appropriate settings and combined with the red coloured bleaching gels (Smart Bleach, SBI) has been shown to be one of the best options for photoactivated dental bleaching. Walsh [68] demonstrated a higher bleaching effect with KTP than with a diode laser based on DOTCAM analysis, a result which was also confirmed in other studies [19, 23, 69]. Its efficacy was also demonstrated for the bleaching of tetracycline discoloured teeth [61]. Temperature elevation in the pulp chamber was also under control when appropriate settings were used in conjunction with a red coloured gel (containing sulphorhodamine B as a chromophore) [19, 24]. The safety of the procedure was demonstrated by an unaltered enamel surface after KTP laser bleaching [25]; no significant differences in the enamel microhardness pre- and posttreatment [68] and no changes in the compositional structure of dentin surfaces were found [69]. Occasional mild postoperative sensitivity was seen during the $12 \mathrm{~h}$ following the procedure as radicals are neutralized by catalase and other pulpal enzymes $[1,68]$. Catalase had been found to protect the dental pulp during vital bleaching procedures [70]. A catalase application was demonstrated to eliminate residual hydrogen peroxide during non-vital bleaching procedures [71].

\section{Conclusions}

(1) It is difficult to draw conclusions for laser bleaching on efficiency and efficacy from the present-day literature because of the difference in concentrations in hydrogen peroxide used, the difference in wavelengths of lasers (especially the diodes) used, the difference in laser settings and protocols used, and differences in bleaching gels used with or without photocatalyst.

(2) Comparative studies evaluating bleaching techniques with high concentrations of hydrogen peroxide and with or without the use of light activation resulted in enhanced lightening. Most often comparable results were found irrespective of light exposure. 
(3) No long-term evaluations for laser enhanced bleaching procedures are available.

(4) Based on the limited number of investigations, at present, only one particular wavelength appears to be able to perform direct photobleaching (or photooxidation), that is, KTP $(532 \mathrm{~nm})$. When KTP is used in combination with a bleaching gel containing a chromophore (sulphorhodamine) allowing the absorption of the laser light, photodynamic reactions can be induced (photochemical activation of the gel with limited photothermal activation). This combination of wavelength and specifically dyed bleaching gel also allows for safe bleaching (no damage of the enamel, no heating of the pulp) when the guidelines of the manufacturer are followed.

(5) At present a number of wavelengths are not recommended for laser bleaching: Nd:YAG, Er:YAG, and $\mathrm{CO}_{2}$. Combination devices consisting of LED-diode laser do not result in enhanced lightening and are in fact not effective. When using high power diode lasers for bleaching care has to be taken so as not to overheat the pulp. Also diode lasers are not really advocated for laser bleaching except when the wavelength is used in combination with a bleaching gel containing wavelength specific absorbers.

(6) With the exception of KTP used in combination with a gel with a specifically red coloured light absorber (sulphorhodamine B) for the green light $(532 \mathrm{~nm})$, laser activated bleaching is solely based on heating of the bleaching gel.

(7) All studies have been conducted with high concentrated hydrogen peroxide gels. This means that the soft tissues have to be thoroughly protected during the in-office power bleaching procedure. No studies were conducted to investigate the safety of laser bleaching procedures on the soft tissues adjacent to the laser activated bleaching gel.

\section{Recommendations for Future Investigations}

Three factors are to be considered when using a light source and should be mentioned in the studies: light intensity, spectral distribution, and irradiation time. Since the total energy depends on light intensity and irradiation time, light curing units with high intensity may allow a reduction in irradiation time. Second generation LEDs present higher power than first generation LEDs. Further research is needed to evaluate if high power (narrow band) LEDs can be used for light-activated bleaching. With the price of a number of laser devices in mind, this technology might be of interest for the activation of bleaching gels.

An important relationship exists among gel colour, laser wavelength, thermal transmission, and clinical efficacy, but not between gel temperature, shade change, and HP concentration. In this respect the use of absorbing substances to increase the radiation absorption (and the temperature in the gel) is known. With the use of $\mathrm{TiO}_{2}$ it has been demonstrated that there is another way to improve dental bleaching without the risk of damaging the pulp. Hence the composition of the gel with the absorbers and additional compounds (agents enabling to catalyse the redox reaction) should also be given in detail.

\section{Conflict of Interests}

The authors declare that there is no conflict of interests regarding the publication of this paper.

\section{References}

[1] L. J. Walsh, "Safety issues relating to the use of hydrogen peroxide in dentistry," Australian Dental Journal, vol. 45, no. 4, pp. 257-269, 2000.

[2] C. H. Abbott, "Bleaching discoloured teeth by means of $30 \%$ perhydrol and the electric light rays," Journal of the Allied Dental Society, vol. 13, p. 259, 1918.

[3] A. Joiner, "The bleaching of teeth: a review of the literature," Journal of Dentistry, vol. 34, no. 7, pp. 412-419, 2006.

[4] W. Buchalla and T. Attin, "External bleaching therapy with activation by heat, light or laser-a systematic review," Dental Materials, vol. 23, no. 5, pp. 586-596, 2007.

[5] M. A. M. Sulieman, "An overview of tooth-bleaching techniques: chemistry, safety and efficacy," Periodontology 2000, vol. 48, no. 1, pp. 148-169, 2008.

[6] J. C. Ontiveros, "In-office vital bleaching with adjunct light," Dental Clinics of North America, vol. 52, no. 2, pp. 241-253, 2011.

[7] A. Joiner, "Review of the effects of peroxide on enamel and dentine properties," Journal of Dentistry, vol. 35, no. 12, pp. 889896, 2007.

[8] M. Goldberg, M. Grootveld, and E. Lynch, "Undesirable and adverse effects of tooth-whitening products: a review," Clinical Oral Investigations, vol. 14, no. 1, pp. 1-10, 2010.

[9] L.-B. He, M.-Y. Shao, K. Tan, X. Xu, and J.-Y. Li, “The effects of light on bleaching and tooth sensitivity during in-office vital bleaching: a systematic review and meta-analysis," Journal of Dentistry, vol. 40, no. 8, pp. 644-653, 2012.

[10] M. Sulieman, M. Addy, and J. S. Rees, "Surface and intra-pulpal temperature rises during tooth bleaching: an in vitro study," British Dental Journal, vol. 199, no. 1, pp. 37-40, 2005.

[11] H. E. Goodis, J. M. White, J. Andrews, and L. G. Watanabe, "Measurement of temperature generated by visible-light-cure lamps in an in vitro model," Dental Materials, vol. 5, no. 4, pp. 230-234, 1989.

[12] K. Luk, L. Tam, and M. Hubert, "Effect of light energy on peroxide tooth bleaching," Journal of the American Dental Association, vol. 135, no. 2, pp. 194-201, 2004.

[13] S. M. D. A. Michida, S. P. Passos, Â. R. K. Marimoto, M. C. V. Garakis, and M. A. M. de Araújo, "Intrapulpal temperature variation during bleaching with various activation mechanisms," Journal of Applied Oral Science, vol. 17, no. 5, pp. 436-439, 2009.

[14] A. Dominguez, J. A. Garcia, A. Costela, and C. Gomez, "Influence of the light source and bleaching gel on the efficacy of the tooth whitening process," Photomedicine and Laser Surgery, vol. 29, no. 1, pp. 53-59, 2011.

[15] E. Klaric, M. Rakic, I. Sever, and Z. Tarle, "Temperature rise during experimental light-activated bleaching," Lasers in Medical Science, 2013. 
[16] B. H. Kivanç, H. D. Arisu, O. I. Ulusoy, B. C. Saglam, and G. G. Gorgul, "Effect of light-activated bleaching on pulp chamber temperature rise: an in vitro study," Australian Endodontic Journal, vol. 16, no. 5, pp. 355-359, 2012.

[17] T. Sari, G. Celik, and A. Usumez, "Temperature rise in pulp and gel during laser-activated bleaching: in vitro," Lasers in Medical Science, 2013.

[18] M. Sulieman, J. S. Rees, and M. Addy, "Surface and pulp chamber temperature rises during tooth bleaching using a diode laser: a study in vitro," British Dental Journal, vol. 200, no. 11, pp. 631-634, 2006.

[19] C. Fornaini, G. Lagori, E. Merigo et al., "Analysis of shade, temperature and hydrogen peroxide concentration during dental bleaching: in vitro study with the KTP and diode lasers," Lasers in Medical Science, vol. 28, no. 1, pp. 1-6, 2013.

[20] N. U. Wetter, M. C. S. Barroso, and J. E. P. Pelino, "Dental bleaching efficacy with diode laser and LED irradiation: an in vitro study," Lasers in Surgery and Medicine, vol. 35, no. 4, pp. 254-258, 2004.

[21] N. U. Wetter, D. A. Walverde, I. T. Kato, and C. D. P. Eduardo, "Bleaching efficacy of whitening agents activated by xenon lamp and 960-nm diode radiation," Photomedicine and Laser Surgery, vol. 22, no. 6, pp. 489-493, 2004.

[22] A. U. Eldeniz, A. Usumez, S. Usumez, and N. Ozturk, "Pulpal temperature rise during light-activated bleaching," Journal of Biomedical Materials Research Part B Applied Biomaterials, vol. 72, no. 2, pp. 254-259, 2005.

[23] C. Zhang, X. Wang, J.-I. Kinoshita et al., "Effects of KTP laser irradiation, diode laser, and LED on tooth bleaching: a comparative study," Photomedicine and Laser Surgery, vol. 25, no. 2, pp. 91-95, 2007.

[24] P. Verheyen, L. J. Walsh, J. Wernisch, U. Schoop, and A. Moritz, "Laser assisted bleaching," in Oral Laser Application, A. Mortiz, F. Beer, K. Goharkhay et al., Eds., pp. 407-448, Quintessence Publishing, Berlin, Germany, 1st edition, 2006.

[25] K. Goharkhay, U. Schoop, J. Wernisch, S. Hartl, R. De Moor, and A. Moritz, "Frequency doubled neodymium:yttriumaluminum-garnet and diode laser-activated power bleaching$\mathrm{pH}$, environmental scanning electron microscopy, and colorimetric in vitro evaluations," Lasers in Medical Science, vol. 24, no. 3, pp. 339-346, 2009.

[26] P. R. Pleffken, A. B. Borges, S. E. De Paiva Gonçalves, and C. R. G. Torres, "The effectiveness of low-intensity red laser for activating a bleaching gel and its effect in temperature of the bleaching gel and the dental pulp," Journal of Esthetic and Restorative Dentistry, vol. 24, no. 2, pp. 126-132, 2012.

[27] T. G. Carrasco, L. D. Carrasco-Guerisoli, and I. C. Fröner, "In vitro study of the pulp chamber temperature rise during lightactivated bleaching," Journal of Applied Oral Science, vol. 16, no. 5, pp. 355-359, 2008.

[28] C. R. Torres, T. M. Caneppele, F. C. Arcas, and A. B. Borges, "In vitro assessment of pulp chamber temperature of different teeth submitted to dental bleaching associated with LED/laser and halogen lamp appliances," General Dentistry, vol. 56, no. 5, pp. 481-486, 2008.

[29] D. S. Coutinho, L. Silveira Jr., R. A. Nicolau, F. Zanin, and A. Brugnera Jr., "Comparison of temperature increase in in vitro human tooth pulp by different light sources in the dental whitening process," Lasers in Medical Science, vol. 24, no. 2, pp. 179-185, 2009.
[30] D. N. Dederich and R. D. Bushick, "Lasers in dentistry: separating science from hype," Journal of the American Dental Association, vol. 135, no. 2, pp. 204-212, 2004.

[31] W. J. Calmon, A. Brugnera Jr., E. Munin et al., "Estudo do aumento de temperatura intra-pulpar gerado pelo clareamento dental," Revista Gaúcha de Odontologia, vol. 52, no. 1, pp. 19-24, 2004.

[32] I. C. R. Cesar, M. L. Redígolo, P. C. S. Liporoni, and E. Munin, "Analyses by photoreflectance spectroscopy and Vickers hardness of conventional and laser-assisted tooth bleaching," American Journal of Dentistry, vol. 18, no. 4, pp. 219-222, 2005.

[33] S. A. McEvoy, "Chemical agents for removing intrinsic stains from vital teeth. II. Current techniques and their clinical application," Quintessence International, vol. 20, no. 6, pp. 379384, 1989.

[34] T. Dostalova, H. Jelinkova, D. Housova et al., "Diode laseractivated bleaching," Brazilian Dental Journal, vol. 15, pp. SI-3SI-8, 2004.

[35] S. B. Berger, V. Cavalli, A. A. Martin et al., "Effects of combined use of light irradiation and 35\% hydrogen peroxide for dental bleaching on human enamel mineral content," Photomedicine and Laser Surgery, vol. 28, no. 4, pp. 533-538, 2010.

[36] S. O. Parreiras, P. Vianna, S. Kossatz, A. D. Loguercia, and A. Reis, "Effects of light activated in-office bleaching on permeability, microhardness, and mineral content of enamel," Operative Dentistry, vol. 29, no. 4, pp. E225-E260, 2014.

[37] I. C. R. Cesar, L. E. S. Soares, L. P. Alves, A. A. Martin, E. Munin, and P. C. S. Liporoni, "Fourier transform-raman and reflectance studies on dental enamel bleached with hydrogen peroxide activated using a light-emitting diode-laser system," Photomedicine and Laser Surgery, vol. 27, no. 6, pp. 913-919, 2009.

[38] J.-H. Son, J.-H. An, B.-K. Kim, I.-N. Hwang, Y.-J. Park, and H.-J. Song, "Effect of laser irradiation on crystalline structure of enamel surface during whitening treatment with hydrogen peroxide," Journal of Dentistry, vol. 40, no. 11, pp. 941-948, 2012.

[39] T. Attin, U. Koidl, W. Buchalla, H. G. Schaller, A. M. Kielbassa, and E. Hellwig, "Correlation of microhardness and wear in differently eroded bovine dental enamel," Archives of Oral Biology, vol. 42, no. 3, pp. 243-250, 1997.

[40] M. T. De Magalhães, R. T. Basting, E. R. De Almeida, and J. E. P. Pelino, "Diode laser effect on enamel microhardness after dental bleaching associated with fluoride," Photomedicine and Laser Surgery, vol. 27, no. 6, pp. 937-941, 2009.

[41] C. P. Turssi, R. J. Schiavoni, M. C. Serra, and I. C. Froner, "Permeability of enamel following light-activated power bleaching," General Dentistry, vol. 54, no. 5, pp. 323-326, 2006.

[42] E. A. Alves, F. K. A. Alves, E. D. J. Campos, and P. Mathias, "Susceptibility to carieslike lesions after dental bleaching with different techniques," Quintessence International, vol. 38, no. 7, pp. e404-409, 2007.

[43] F. O. Araujo, L. N. Baratieri, and É. Araújo, "In situ study of in-office bleaching procedures using light sources on human enamel microhardness," Operative Dentistry, vol. 35, no. 2, pp. 139-146, 2010.

[44] D. C. Can-Karabulut and B. Karabulut, "Shear bond strength to enamel after power bleaching activated by different sources," European Journal of Esthetic Dentistry, vol. 5, no. 4, pp. 382-396, 2010.

[45] A. E. Souza-Gabriel, L. O. Vitussi, C. Milani, E. Alfredo, D. C. F. Messias, and Y. T. C. Silva-Sousa, "Effect of bleaching protocols 
with 38\% hydrogen peroxide and post-bleaching times on dentin bond strength," The Brazilian Dental Journal, vol. 22, no. 4, pp. 317-321, 2011.

[46] C.-H. Lin, T.-M. Chou, J.-H. Chen et al., "Evaluation of the effect of laser tooth whitening," International Journal of Prosthodontics, vol. 21, no. 5, pp. 415-418, 2008.

[47] R. F. Mondelli, J. F. de Azevedo, A. C. Francisconi, C. M. de Almeida, and S. K. Ishikiriama, "Comparative clinical study of the effectiveness of different dental bleaching methods-two year follow-up," Journal of Applied Oral Science, vol. 20, no. 4, pp. 435-443, 2012.

[48] S. Kossatz, A. P. Dalanhol, T. Cunha, A. Loguercio, and A. Reis, "Effect of light activation on tooth sensitivity after in-office bleaching," Operative Dentistry, vol. 36, no. 3, pp. 251-257, 2011.

[49] J. Caviedes-Bucheli, G. Ariza-García, S. Restrepo-Méndez, N. Ríos-Osorio, N. Lombana, and H. R. Muñoz, "The effect of tooth bleaching on substance $\mathrm{P}$ expression in human dental pulp," Journal of Endodontics, vol. 34, no. 12, pp. 1462-1465, 2008.

[50] L. C. D. A. G. D. Almeida, H. Riehl, P. H. D. Santos, M. L. M. M. Sundfeld, and A. L. F. Briso, "Clinical evaluation of the effectiveness of different bleaching therapies in vital teeth," The International Journal of Periodontics \& Restorative Dentistry, vol. 32, no. 3, pp. 303-309, 2012.

[51] J. Martin, E. Fernandez, V. Bahamondes et al., "Dentin hypersensitivity after teeth bleaching with in-office systems. Randomized clinical trial," American Journal of Dentistry, vol. 26, no. 1, pp. 10-14, 2013.

[52] G. Moncada, D. Sepúlveda, K. Elphick et al., "Effects of light activation, agent concentration, and tooth thickness on dental sensitivity after bleaching," Operative Dentistry, vol. 38 , no. 5, pp. 467-476, 2013.

[53] D. A. Lima, F. H. Aguiar, P. C. Liporoni, E. Munin, G. M. B. Ambrosano, and J. R. Lovadino, "In vitro evaluation of the effectiveness of bleaching agents activated by different light sources," Journal of Prosthodontics, vol. 18, no. 3, pp. 249-254, 2009.

[54] I. T. Gontijo, R. S. Navarro, A. L. Ciamponi, and D. M. Zezell, "Whitening techniques using the diode laser and halogen lamp in human devitalized primary teeth," Journal of Dentistry for Children, vol. 75, no. 2, pp. 164-167, 2008.

[55] M. Sulieman, E. MacDonald, J. S. Rees, and M. Addy, "Comparison of three in-office bleaching systems based on 35\% hydrogen peroxide with different light activators," American Journal of Dentistry, vol. 18, no. 3, pp. 194-197, 2005.

[56] M. Marcondes, M. P. G. Paranhos, A. M. Spohr et al., "The influence of the Nd:YAG laser bleaching on physical and mechanical properties of the dental enamel," Journal of Biomedical Materials Research Part B Applied Biomaterials, vol. 90, no. 1, pp. 388-395, 2009.

[57] A. Strobl, N. Gutknecht, R. Franzen, R.-D. Hilgers, F. Lampert, and J. Meister, "Laser-assisted in-office bleaching using a neodymium: yttrium-aluminum-garnet laser: an in vivo study," Lasers in Medical Science, vol. 25, no. 4, pp. 503-509, 2010.

[58] S. Gurgan, F. Y. Cakir, and E. Yazici, "Different light-activated in-office bleaching systems: a clinical evaluation," Lasers in Medical Science, vol. 25, no. 6, pp. 817-822, 2010.

[59] N. U. Wetter, E. P. Branco, A. M. Deana, and J. E. P. Pelino, "Color differences of canines and incisors in a comparative long-term clinical trial of three bleaching systems," Lasers in Medical Science, vol. 24, no. 6, pp. 941-947, 2009.
[60] F. C. Marson, L. G. Sensi, L. C. C. Vieira, and É. Araújo, “Clinical evaluation of in-office dental bleaching treatments with and without the use of light-activation sources," Operative Dentistry, vol. 33, no. 1, pp. 15-22, 2008.

[61] M. Kuzekanani and L. J. Walsh, "Quantitative analysis of KTP laser photodynamic bleaching of tetracycline-discolored teeth," Photomedicine and Laser Surgery, vol. 27, no. 3, pp. 521-525, 2009.

[62] J. Kinoshita, H. Jafarzadeh, and M. Forghani, "Vital bleaching of tetracycline-stained teeth by using KTP laser: a case report," European Journal of Dentistry, vol. 3, no. 3, pp. 229-232, 2009.

[63] G. Lagori, P. Vescovi, E. Merigo, M. Meleti, and C. Fornaini, "The bleaching efficiency of KTP and diode $810 \mathrm{~nm}$ lasers on teeth stained with different substances: an in vitro study," Laser Therapy, vol. 23, no. 1, pp. 21-30, 2014.

[64] Z. Y. Bennett and L. J. Walsh, "Efficacy of LED versus KTP laser activation of photodynamic bleaching of tetracycline-stained dentine," Lasers in Medical Science, 2014.

[65] "Council directive 2011/84/EU of 20 September 2011 amending directive 76/768/EEC; concerning cosmetic products for the purpose of adapting Annex III thereto to technical progress," Official Journal of the European Union, pp. 283/36-283/38, 2011.

[66] J. W. Baik, F. A. Rueggeberg, and F. R. Liewehr, "Effect of light-enhanced bleaching on in vitro surface and intrapulpal temperature rise," Journal of Esthetic and Restorative Dentistry, vol. 13, no. 6, pp. 370-378, 2001.

[67] J. Caviedes-Bucheli, M. M. Azuero-Holguin, J. A. Correa-Ortiz et al., "Effect of experimentally induced occlusal trauma on substance $\mathrm{P}$ expression in human dental pulp and periodontal ligament," Journal of Endodontics, vol. 37, no. 5, pp. 627-630, 2011.

[68] L. J. Walsh, "The current status of laser applications in dentistry," Australian Dental Journal, vol. 48, no. 3, pp. 146-155, 2003.

[69] R. J. G. De Moor and K. Vanderstricht, "The use of KTP, an added value for tooth bleaching," Journal of Oral Laser Applications, vol. 9, no. 4, pp. 219-226, 2009.

[70] W. H. Bowles and H. Burns Jr., "Catalase/peroxidase activity in dental pulp," Journal of Endodontics, vol. 18, no. 11, pp. 527-529, 1992.

[71] I. Rotstein, "Role of catalase in the elimination of residual hydrogen peroxide following tooth bleaching," Journal of Endodontics, vol. 19, no. 11, pp. 567-569, 1993. 


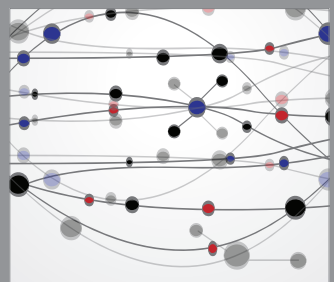

The Scientific World Journal
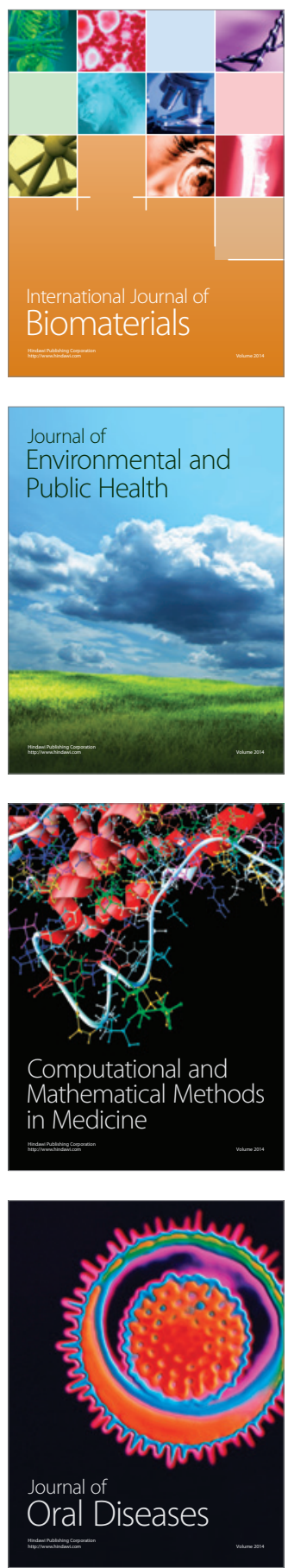
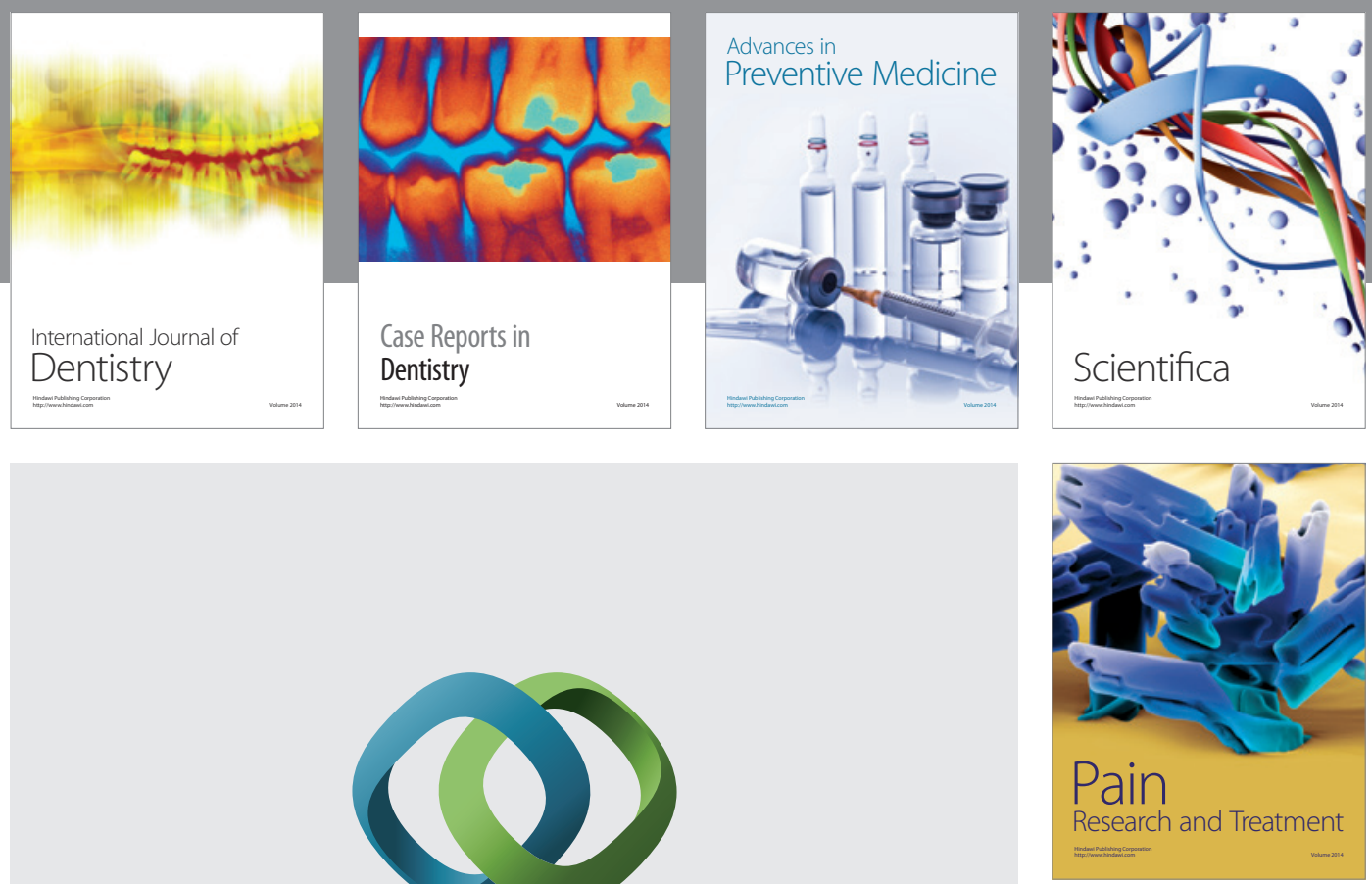

\section{Hindawi}

Submit your manuscripts at

http://www.hindawi.com
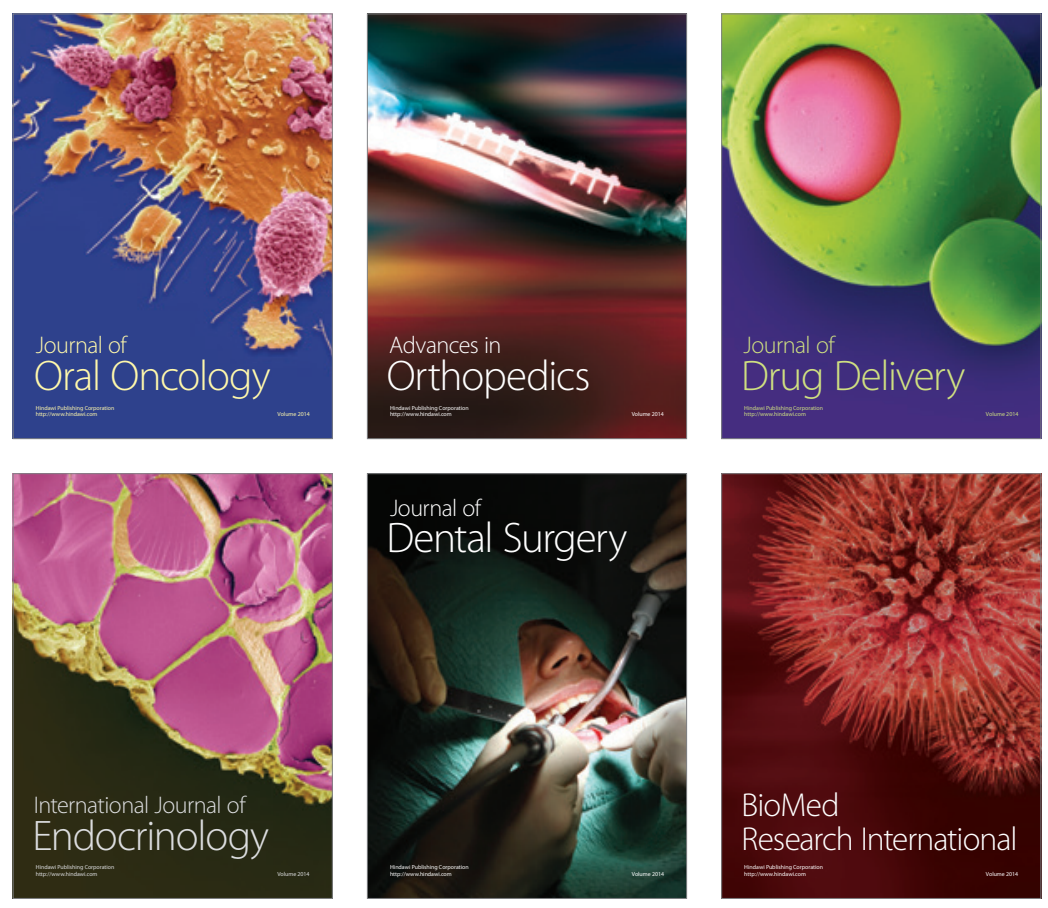

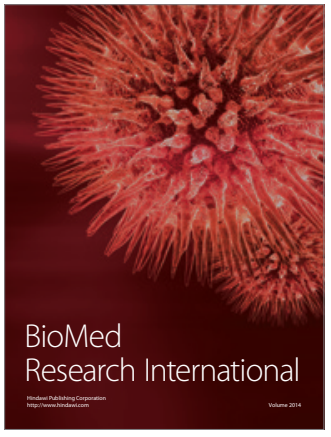

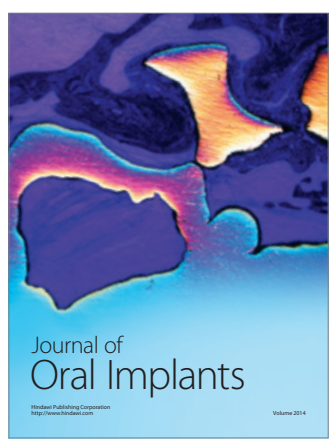
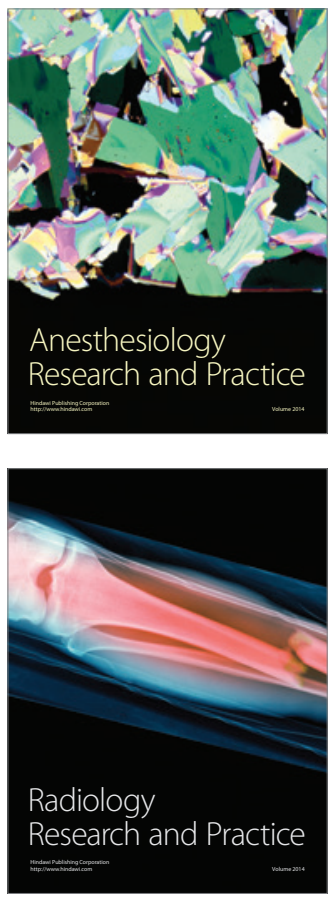